\title{
Detection of the Specific Recognition Site for the Intestinal Elastase-Stx2D Activation, by Pcr and Sequencing Methods, in STEC eae-Negative Isolates of Different Origin in Argentina.
}

\author{
Elizabeth Miliwebsky (I), Carolina Carbonari (I), Cristina Lema (I), \\ Marta Rivas (I), Isabel Chinen (I) \\ (I) INEI-ANLIS - INEI-ANLIS “Dr. Carlos G. Malbrán” (Av. Vélez Sarsfield 563, Buenos Aires, \\ Argentina)
}

\section{Resumo}

The international standard methods for food control, requires the detection of Shiga toxin (Stx)-producing Escherichia coli (STEC) O157:H7 and 6 serogroups eae(+), O26, O45, O103, O145, O111 and O121 ("Big Six"), a pathogenic risk group for public health. In Argentina, STEC O157:H7 is the main etiologic agent that cause hemolytic uremic syndrome (HUS) and outbreaks, followed by STEC O145:NM and O26:H11. However, eae(-) strains are detected with less frequency, associated to severe human disease. Stx is the major virulence factor implicated in the pathogenesis of STEC infections. $\mathrm{AB}_{5}$ toxin is classified in two types, Stx 1 and Stx2, and 5 different subtypes. Stx2d activatable has been described particularly in eae(-) STEC strains associated with severe illnesses like HUS. The designation of Stx2d activatable was given for its capacity of being activated by human intestinal mucus added in cultured cells assay showing an enhance increase of the Stx2d citotoxicity. Stx2dA subunit possesses two specific amino acid substitutions, Ser291 and Glu297, which contribute to the recognition by the intestinal elastase of the site to cleave the A2 subunit, and produces the activatable form. The aim was to compare the performance of two molecular methods for $\mathrm{stx}_{2 \mathrm{~d}}$ detection in eae(-) STEC strains. A total of 55 eae(-) Stx2-STEC strains of 15 different serotypes isolated from human (H), food (F) and animal (A), during 2005-2013 
period, were studied. PCR for $\mathrm{stx}_{2 \mathrm{~d}}$ gene and Sanger sequencing method for amplified DNA fragment ( $890 \mathrm{pb}$ ) associated with elastase-recognition site using ABI 3500, were performed. The sequences were analyzed by BioEdit program v.7.0.4.1 (2005). Twenty (36.4\%) strains were positive for $\mathrm{stx}_{2 \mathrm{~d}}$ by PCR, and carried the recognition site for elastase, identified by sequencing method. Stx2d was detected in the following serotypes: O8:H19 $(\mathrm{H}=1 / \mathrm{A}=1), \mathrm{O} 20: \mathrm{H} 19(\mathrm{H}=1 / \mathrm{F}=1), \mathrm{O} 22: \mathrm{H} 8(\mathrm{H}=1 / \mathrm{F}=2, \mathrm{~A}=1), \mathrm{O} 91: \mathrm{H} 21$ $(\mathrm{H}=3 / \mathrm{F}=2 / \mathrm{A}=1), \mathrm{O} 113: \mathrm{H} 21(\mathrm{~F}=1 / \mathrm{A}=1), \mathrm{ONT}: \mathrm{H} 8(\mathrm{~F}=1), \mathrm{ONT}: \mathrm{H} 19(\mathrm{~F}=2)$, and ONT:HNT $(\mathrm{F}=1)$. The PCR proved to be as efficient as sequencing, to be implemented for a rapid identification of marker sequences of Stx2d in STEC strains. At present, non-O157 STEC represents a risk for public health and food industry due to the international market requirements. The detection of STEC Stx $2 \mathrm{~d}(+)$ in food is important and should be included in the surveillance of these pathogens.

Palavras-Chave: STEC, Stx2 activable, SUH Agência de Fomento: 